\title{
Assessment of depression as a comorbidity in patients of diabetes mellitus
}

\author{
Namrata Chhabra ${ }^{1}$, Amandeep Kaur ${ }^{2, *}$, Sarah Chhabra ${ }^{3}$, Sahiba Kukreja ${ }^{4}$ \\ ${ }^{1}$ Professor \& HOD, ${ }^{2}$ Associate Professor, ${ }^{3}$ Lecturer, ${ }^{4}$ Professor \& HOD, Dept. of Biochemistry, ${ }^{1,3}$ Sir Seewoosagur Ramgoolam \\ Medical College, Belle Rive, Mauritius, ${ }^{2,4}$ Sri Guru Ram Das Institute of Medical Sciences \& Research, Amritsar, Punjab, India
}

*Corresponding Author:

Email: amandeepbest@gmail.com

Received: $12^{\text {th }}$ October, 2017

Accepted: $19^{\text {th }}$ December, 2017

\begin{abstract}
Introduction: The prevalence of diabetes mellitus has reached epidemic levels globally. Depression as a comorbidity in patients with Diabetes Mellitus has been reported by many studies. The coexistence of diabetes and depression is associated with significant morbidity, mortality, and increased healthcare cost. The reports of studies are conflicting and the exact mechanisms linking depression and diabetes are unclear.

Aim and Objective: The aim of the study was to determine the prevalence as well as the correlation of depression with socio demographic profile, duration of disease state, presence of complications and effect of therapeutic intervention in patients with Diabetes mellitus.

Materials and Methods: A cross sectional survey was conducted with an aim of assessing depression as a comorbidity in patients with diabetes mellitus. Depression was assessed using the patient health questionairre-9 (PHQ-9).

Results: Depression as defined by PHQ score $\geq 5$ was present in $45 \%$ of the individuals. Severe depression (PHQ score $\geq 15$ ) was present in $8 \%$ subjects, moderate depression (PHQ score $\geq 10$ ) in $14 \%$ subjects, and mild depression was present in $23 \%$ of subjects. Coexisting depression in patients with diabetes was associated with decreased adherence to treatment, poor metabolic control, higher complication rates, decreased quality of life and increased disability. Depression was significantly more prevalent in rural subjects (59\%) as compared to urban ones (26\%).

Conclusion: Coordinated strategies for clinical care are necessary to improve clinical outcomes and reduce the burden of illness. Currently, recognition of depression among individuals with diabetes is suboptimal, therefore global approaches to establish coordinated, multifaceted interventions to improve early recognition of depression and early initiation of treatment for depression are required to reduce the worldwide burden of depression among individuals with diabetes.
\end{abstract}

Keywords: Diabetes mellitus, Depression, PHQ- Patient health questionnaire.

\section{Introduction}

Diabetes and Depression are major worldwide health problems responsible for profound morbidity and mortality in the general population. The global prevalence of diabetes has nearly doubled since 1980, rising from $4.7 \%$ to $8.5 \%$ in the adult population. ${ }^{1}$ As per International Diabetes Federation report, there were 366 million people with diabetes in 2011, and this number is estimated to rise to 552 million by $2030 .^{2}$ Depression as a comorbidity in patients with Diabetes Mellitus, has been reported by many studies. Approximately 340 million people worldwide are suffering from depression including 18 million in the United States. ${ }^{3}$ Patients with diabetes mellitus are twice at risk of developing depression than the general population. ${ }^{4}$ The worldwide prevalence of depression amongst individuals with diabetes appears to vary by diabetes type and amongst developed and developing nations.

Depression is a modifiable risk factor for diabetes mellitus and diabetes as a chronic illness increases the risk of onset of depression. A bidirectional causal relationship exists between diabetes and depression. Both these disorders are projected to be among the five leading causes of disease burden by $2030 .^{5}$ Data explaining the true prevalence and the correlations of depressive symptoms with diabetic, or the sociodemographic profile are either limiting, or the reports have been conflicting. The recognition and addressal of this association can have profound implications on prevention and treatment of these disorders.

\section{Aims}

In the light of the above-mentioned facts the study was aimed to recognize and address the association of depression as a comorbidity in patients of diabetes mellitus.

\section{Objective}

1. To determine the presence of depressive symptoms in patients of diabetes mellitus

2. To determine the correlation of depressive symptoms (if present) with socio demographic profile, disease history and the presence of complication in Diabetic individuals.

3. To address the association of depression as a comorbidity in diabetic individuals.

\section{Study design}

After the approval from Institutional ethical committee, a cross- sectional survey was conducted for 
3 months from including the clinically proven cases of diabetes mellitus in the age range of 25-75 years attending the wards and medical OPD units.

Inclusion criteria: The patients:

1. with fasting glucose $>126 \mathrm{mg} / \mathrm{dl}$, or

2. with random blood glucose $>200 \mathrm{mg} / \mathrm{dl}$, or

3. known diabetic on regular treatment, or

4. Known diabetic with one or more complications were included as subjects of the study.

Exclusion criteria: The undiagnosed or suspected cases of diabetes mellitus, patients on antidepressant drugs or with a family history of depression; and the patients with gastrointestinal, pulmonary, hepatic, renal, dermatological, musculoskeletal, or other comorbidities were excluded from the study.

\section{Materials and Methods}

A written informed consent was taken from all the study subjects. The Patient Health Questionnaire-9 (PHQ-9) -(Table-1) was used for the assessment of depressive symptoms. The PHQ-9 is the depression module, which scores each of the 9 DSM-IV criteria as $0=$ not at all, $1=$ several days, $2=$ more than $1 / 2$ of the days, $3=$ nearly every day. ${ }^{6}$ The study instrument was piloted on several individuals and validated for suitability.

The symptoms experienced by participants during the 2-week period before the survey were assessed. Based on participant's responses to the frequency of any symptom, a total score ranging from 0 to 27 was obtained. PHQ-9 scores of (1-4), (5-9), (10-14), (1519) and (20-27)-represented minimal, mild, moderate, moderately severe, and severe depression, respectively. ${ }^{6}$

The correlation of depressive symptoms was determined with socio-demographic profile, vigorous physical exercise (at least once a week), daily consumption of alcohol, BMI (body mass index), disease history, presence of hypertension, and diabetes related complications.

The fasting blood glucose (GOD-POD method) and $\mathrm{HbA1c}$ (capillary electrophoresis) levels were estimated for all the study subjects.

\section{Statistical analysis}

Data were analyzed using IBM SPSS statistic software version 24.0 for Windows. Numerical data were presented as mean \pm standard deviation or percentages. Differences in characteristics between participants were tested with unpaired t-test for normally distributed variables, with the Wilcoxon rank sum test for skewed variables, and with the Chi-square test for categorical variables. The significance level was set at $5 \%$.

\section{Results}

A total of 200 diabetic patients participated in the study. Their baseline characteristics and disease statistics have been shown in Table 1 and 2 respectively. $45 \%$ of the diabetic subjects were found with depressive symptoms ranging from minimal to severe. Moderate depression was observed in maximum number of study subjects (Table 3). The variables such as advancing age, female gender, rural background, alcohol consumption, cigarette smoking, physical inactivity and obesity were found as the major determinants of depression. Statistically highly significant variations in PHQ-9 scores were observed in these categories. (Table 4). PHQ score positively correlated with BMI, Glycated $\mathrm{Hb}$ and duration of diabetes.

\section{Table 1: Baseline characteristics}

\begin{tabular}{|c|c|c|c|}
\hline Attributes & Groups & $\begin{array}{c}\text { Number of subjects } \\
\text { (Total- 200) }\end{array}$ & Percentage \\
\hline \multirow{2}{*}{ 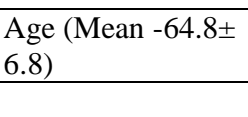 } & $25-50$ & 60 & 30 \\
\hline & $51-75$ & 140 & 70 \\
\hline \multirow[t]{2}{*}{ Gender } & Males & 86 & 43 \\
\hline & Females & 114 & 57 \\
\hline \multirow[t]{2}{*}{ Education } & Uneducated & 34 & 17 \\
\hline & Educated & 166 & 83 \\
\hline \multirow[t]{3}{*}{ Social status } & Married & 160 & 80 \\
\hline & Single & 33 & 16.5 \\
\hline & Divorced & 7 & 3.5 \\
\hline \multirow[t]{2}{*}{ Place of residence } & Rural & 68 & 34 \\
\hline & Urban & 132 & 66 \\
\hline \multirow{2}{*}{$\begin{array}{l}\text { Professional } \\
\text { information }\end{array}$} & Employed & 154 & 77 \\
\hline & Unemployed & 46 & 23 \\
\hline Smoking & $\begin{array}{l}\text { Non- } \\
\text { Smoker }\end{array}$ & 126 & 63 \\
\hline $\begin{array}{l}\text { Daily Alcohol } \\
\text { Consumption }\end{array}$ & $\begin{array}{l}\text { Non- } \\
\text { Alcoholic }\end{array}$ & 89 & 44.5 \\
\hline
\end{tabular}




\begin{tabular}{|l|l|c|c|}
\hline & Alcoholic & 111 & 55.5 \\
\hline $\begin{array}{l}\text { Vigorous physical } \\
\text { exercise at least } \\
\text { once a week }\end{array}$ & No Exercise & 121 & 60.5 \\
\hline & $\begin{array}{l}\text { Some } \\
\text { Exercise }\end{array}$ & 79 & 39.5 \\
\hline $\begin{array}{l}\text { BMI-Body Mass } \\
\text { Index }(\mathrm{Kg} / \mathrm{m} 2)\end{array}$ & $<30$ & 42 & 21 \\
\hline & $>30$ & 158 & 79 \\
\hline
\end{tabular}

Table 2: Disease statistics

\begin{tabular}{|l|l|c|c|}
\hline \multicolumn{1}{|c|}{ Attributes } & Groups & $\begin{array}{c}\text { Number of } \\
\text { subjects } \\
\text { (Total-200) }\end{array}$ & Percentage \\
\hline Type of diabetes & Type 1 & 23 & 11.5 \\
\hline & Type 2 & 177 & 88.5 \\
\hline Duration of Diabetes & $<5$ years & 98 & 49 \\
\hline & $>5$ years & 102 & 51 \\
\hline Family history of diabetes & Positive & 86 & 43 \\
\hline & Negative & 114 & 57 \\
\hline Hypertension & Present & 89 & 44.5 \\
\hline & Absent & 111 & 55.5 \\
\hline Diabetic complications & Present & 91 & 45.5 \\
\hline & Absent & 109 & 54.5 \\
\hline HbA1c & $<6$ & 30 & 15 \\
\hline & $>6-10$ & 110 & 55 \\
\hline & $>10$ & 60 & 30 \\
\hline
\end{tabular}

Table 3: Prevalence of Depression in diabetic patients

\begin{tabular}{|l|l|c|c|}
\hline \multicolumn{1}{|c|}{ Score } & Interpretations & $\begin{array}{c}\text { Number of } \\
\text { subjects }\end{array}$ & Percentage \\
\hline $1-4$ & Minimal & 18 & $\mathbf{9}$ \\
\hline $5-9$ & Mild & 22 & 11 \\
\hline $10-14$ & Moderate & 32 & 16 \\
\hline $15-19$ & $\begin{array}{l}\text { Moderately } \\
\text { Severe }\end{array}$ & 16 & 8 \\
\hline $20-27$ & Severe & 2 & 1 \\
\hline $\begin{array}{l}\text { Total } \\
\text { prevalence }\end{array}$ & Minimal- Severe & 90 & 45 \\
\hline
\end{tabular}

Table 4: Association of variables with PHQ-9 score

\begin{tabular}{|l|c|}
\hline Variable & P value \\
\hline Age & 0.025 \\
\hline Female & $<0.001$ \\
\hline Married & $<0.001$ \\
\hline Rural & $<0.001$ \\
\hline Educated & $<0.001$ \\
\hline Smoking & $<0.001$ \\
\hline Daily consumption of Alcohol & $<0.001$ \\
\hline No Physical exercise & $<0.001$ \\
\hline BMI- $>30$ & $<0.001$ \\
\hline Family history of diabetes & $<0.01$ \\
\hline Duration of disease & $<0.01$ \\
\hline Fasting blood glucose & 0.08 \\
\hline HbA1c & $<0.01$ \\
\hline
\end{tabular}

\section{Discussion}

Out of the total 200 patients, $90(45 \%)$ were found with symptoms of depression. Similar results have been reported by many other studies. ${ }^{7-10}$ The studies have reported higher risk of developing depression in persons with diabetes than the general population. ${ }^{11} \mathrm{~A}$ meta-analysis of 42 published studies that included 21,351 adults found that the prevalence of major depression in people with diabetes was $11 \%$ and the 
prevalence of clinically relevant depressive symptoms was $31 \% .^{12}$

The prevalence of depression among females was higher than their male counterparts with diabetes. The higher prevalence among females with diabetes than their male counterparts with diabetes has been reported by several studies. ${ }^{12}$ Multiple reasons could be attributed to this observation: stress of family, workplace based stress, lifestyle, and socio-economic factors.

A higher prevalence of depression was observed in diabetics with a rural background, as compared to urban ones, and the difference was statistically significant. It may be related to socioeconomic status. The individuals with low socio-economic status face the dual burdens of paying for health care, and meeting the needs of their families. The diagnosis of T2DM and its poor understanding in rural areas may be an additional stress causing depression in these people. ${ }^{10}$

Statistically significant variations were observed between depression and advancing age, family history of diabetes, duration of disease, glycemic control, and microvascular complications. The prevalence of depression in patients with type 2 diabetes mellitus was higher than type 1 , and the differences were highly significant statistically. The greater risk of type 2 diabetes in individuals with depression is believed to result from an increase in counter-regulatory hormone release and function, alterations in the glucose transport system, and increased immune-inflammatory activation. ${ }^{13}$ These physiologic alterations are thought to contribute to insulin resistance and beta islet cell dysfunction, which ultimately leads to the development of type 2 diabetes. Different forms of emotional stress are associated with an increased risk for the development of type 2 diabetes, particularly depression, general emotional stress, anxiety, anger/hostility, sleep disturbances and workplace based stress.

Studies have reported a bidirectional pathway between diabetes and depression. Depression in individuals with both type 1 and type 2 diabetes is a result of chronic psychosocial stress of having a chronic medical condition. ${ }^{14}$ insulin resistance and resultant hyperglycemia often resolve when patients recover from depression. ${ }^{15,16}$

The higher risk of complications and poor quality of life in diabetic patients with depression as comorbidity has been a reported by a number of studies. Patients with coexisting diabetes and depression have shown poor self-management by not sticking to a strict diet regimen, maintaining good physical activity, checking blood glucose levels on a regular basis and refilling medications. ${ }^{17,18}$ These individuals are also more likely to have 3 or more cardiac risk factors (obesity, sedentary life style, smoking, impaired glucose tolerance) compared to patients with diabetes alone. ${ }^{19,20}$
To summarize, Depression in patients with diabetes mellitus represents a complex phenomenon which is the result of complicated interactions between biological, genetic and psycho-social factors. It is important to diagnose and treat depression at an early stage in the diabetic population as this seems to have positive effects on both depressive symptoms and glycemic control.

\section{Conclusion}

There is high prevalence of depression in individuals suffering from Diabetes mellitus in North Indian population. Depression should be assessed in all patients with diabetes, irrespective of gender, duration of diabetes, glycemic control or presence/absence of microvascular complications.

\section{Recommendations}

Currently, recognition of depression among individuals with diabetes is suboptimal. Global approaches to establish coordinated, multifaceted interventions to improve early recognition of depression and early initiation of treatment for depression are required to reduce the worldwide burden of depression among individuals with diabetes.

\section{Conflicts of interest: None}

\section{Acknowledgements}

I thankfully acknowledge Professor (Dr.) Ameetha for her unconditional support and guidance.

\section{References}

1. Global report on Diabetes- World Health Organization.

2. International Diabetes Federation, The human, social and economic impact of diabetes. Available at:

http://www.idf.org/home/index.cfm?node=41. 2008.

3. L.E. Egede. Disease-focused or integrated treatment: diabetes and depression. Med. Clin. North Am. 2006;90(4):627-46.

4. J.F. Greden. Physical symptoms of depression: unmet needs. J. Clin. Psychiatry. 2003;64(7):5-11.

5. C.M. Michaud, C.J. Murray, B.R. Bloom. Burden of disease - implications for future research. JAMA. 2001;285(5):535-9.

6. Kroenke K, Spitzer RL, Williams JB. The PHQ-9: validity of a brief depression severity measure. J Gen Intern Med. 2001 Sep;16(9):606-13.

7. Roy T, Lloyd CE, Parvin M, Mohiuddin KG, Rahman M. Prevalence of co-morbid depression in out-patients with type 2 diabetes mellitus in Bangladesh. BMC Psychiatry 2012;12:123.

8. Madhu M, Abish A, Anu K, Jophin RI, Kiran AM, Vijayakumar K. Predictors of depression among patients with diabetes mellitus in Southern India. Asian J Psychiatr. 2013;6:313-7.

9. Raval A, Dhanaraj E, Bhansali A, Grover S, Tiwari P Prevalence and determinants of depression in type 2 diabetes patients in a tertiary care center. Indian J Med Res. 2010;132:195-200. 
10. Amit Thour, Subhash Das, Tejasav Sehrawat, Yashdeep Gupta. Depression among patients with diabetes mellitus in North India evaluated using patient health questionnaire-9. Indian journal of endocrinology and metabolism. 2015; 19(6),252-5.

11. Ali S, Stone MA, Peters JL, Davies MJ, Khunti K. The prevalence of comorbid depression in adults with type 2 diabetes: a systematic review and meta- analysis. Diabet Med. 2006;23:1165-73.

12. Anderson RJ, Freedland KE, Clouse RE, Lustman PJ. The prevalence of comorbid depression in adults with diabetes: a meta-analysis. Diabetes Care. 2001; 24(6):1069-78.

13. Musselman DL, Betan E, Larsen H, Phillips LS. Relationship of depression to diabetes types 1 and 2: epidemiology, biology, and treatment. Biol Psychiatry. 2003; 54(3):317-29.

14. Nouwen A, Winkley K, Twisk J, Lloyd CE, Peyrot M, Ismail K, et al. European Depression in Diabetes (EDID) Research Consortium: Type 2 diabetes mellitus as a risk factor for the onset of depression: a systematic review and metaanalysis. Diabetologia. 2010,53(12):2480-6.
15. Okamura F, Tashiro A, Utumi A, Imai T, Suchi T, Tamura D, et al. Insulin resistance in patients with depression and its changes during the clinical course of depression: minimal model analysis. Metabolism. 2000;49(10):1255-60.

16. B, Schweiger U, Deuschle M, Heuser I. Major depression and impaired glucose tolerance. Exp Clin Endocrinol Diabetes. 2000;108(3):187-90.

17. Lin EH, Katon W, Von Korff M, Rutter C, Simon GE, Oliver M, et al. Relationship of depression and diabetes self-care, medication adherence, and preventive care. Diabetes Care. 2004;27:2154-60.

18. Ciechanowski PS, Katon WJ, Russo JE. Depression and diabetes: impact of de- pressive symptoms on adherence, function, and costs. Arch Intern Med. 2000;160:3278-85.

19. Katon WJ, Lin EH, Russo J, Von Korff M, Ciechanowski $\mathrm{P}$, Simon G, et al. Cardiac risk factors in patients with diabetes mellitus and major depression. J Gen Intern Med. 2004;19:1192-9.

20. Patel V. A short review on the association between depression and diabetes. Int J Med Sci Public Health. 2014;3:3-5.

Annexure: Patient health questionnaire (9)

PHQ-9 (Over the last two weeks, how often have you been bothered by any of the following problems?)

\begin{tabular}{|l|l|l|l|l|l|}
\hline S. No. & \multicolumn{1}{|c|}{ Context } & $\begin{array}{c}\text { Not at } \\
\text { all } \\
\text { (0) }\end{array}$ & $\begin{array}{c}\text { Several } \\
\text { Days } \\
\text { (1) }\end{array}$ & $\begin{array}{c}\text { More than } \\
\text { half the } \\
\text { days (2) }\end{array}$ & $\begin{array}{c}\text { Nearly } \\
\text { every day } \\
\text { (3) }\end{array}$ \\
\hline 1 & Little interest or pleasure in doing things? & & & & \\
\hline 2 & Feeling down, depressed, or hopeless? & & & & \\
\hline 3 & $\begin{array}{l}\text { Trouble falling or staying asleep, or } \\
\text { sleeping too much? }\end{array}$ & & & & \\
\hline 4 & Feeling tired or having little energy? & & & & \\
\hline 5 & Poor appetite or overeating? & & & & \\
\hline 6 & $\begin{array}{l}\text { Feeling bad about yourself - or that you are } \\
\text { a failure or have let yourself or your family } \\
\text { down? }\end{array}$ & & & & \\
\hline 7 & $\begin{array}{l}\text { Trouble concentrating on things, such as } \\
\text { reading the newspaper or watching } \\
\text { television? }\end{array}$ & & & & \\
\hline 8 & $\begin{array}{l}\text { Moving or speaking so slowly that other } \\
\text { people could have noticed? } \\
\text { Or the opposite - being so fidgety or } \\
\text { restless that you have been moving around } \\
\text { a lot more than usual? }\end{array}$ & & & & \\
\hline 9 & $\begin{array}{l}\text { Thoughts that you would be better off } \\
\text { dead, or of hurting yourself in some way? }\end{array}$ & & & & \\
\hline & Total score & & & \\
\hline
\end{tabular}

